\title{
Um estudo exploratório sobre os aspectos motivacionais de uma atividade não escolar para o ensino da Astronomia ${ }^{+*}$
}

\author{
Rodolfo Langhi ${ }^{1}$ \\ Universidade Estadual Paulista - Campus Bauru \\ Bruno Andrade Martins ${ }^{2}$ \\ Universidade Federal de Mato Grosso do Sul \\ Campo Grande - MS
}

\section{Resumo}

Esta pesquisa teve o objetivo de estudar os aspectos que conduzem à motivação para aprender Astronomia por parte do público-alvo em um espaço não escolar. Apesar de a literatura da área apontar com frequência que a Astronomia é considerada motivadora, não há trabalhos com fundamentação teórica sobre conceitos específicos que envolvam a motivação. Utilizando atividades de observação da Lua com telescópios disponíveis ao público em um ambiente não escolar, visamos responder à questão central: a partir dos aspectos motivacionais encontrados nos participantes da atividade em questão, podemos considerar que estes apresentaram indícios de motivação intrínseca e que a Astronomia foi de fato um fator motivacional para a participação na atividade? Para o estudo da motivação, usamos como referencial teórico a Teoria da Autodeterminação, que se dedica a estudar a personalidade e a motivação humana como as motivações intrínseca e extrínseca. Para nortear a análise, fundamentamo-nos no referencial metodológico qualitativo da Análise Textual Discursiva, que busca a compreensão das novas interpretações a partir dos dados da pesquisa. Nossos resultados apontam que a Astronomia pode ser considerada motivadora para casos semelhantes ao aqui estudado, pois foram diagnosticados, em uma grande parte dos dados, indícios de motivação intrínseca nos participantes. Os resultados também mostraram que os espaços não escolares de ensino podem com-

\footnotetext{
${ }^{+}$An exploratory study of the motivational aspects of a non-school activity for teaching of Astronomy

* Recebido: março de 2017.

Aceito: outubro de 2017.

1 E-mail: rlanghi@fc.unesp.br; ${ }^{2}$ E-mail: martinsfisica@gmail.com
} 
plementar o trabalho da escola na alfabetização e letramento científico da comunidade, mostrando assim a importância de se desenvolver atividades como esta a fim de contribuir para a aprendizagem.

Palavras-chave: Educação em Astronomia; Ambientes Não Escolares; Teoria da Autodeterminação; Motivação.

\begin{abstract}
This research aimed to study the aspects that lead to motivation to learn Astronomy in a non-school environment. Although the literature of the area frequently points out that Astronomy is considered motivating, there is no work with theoretical framework of specific concepts that involves motivation. By using activities with telescopes to observe the Moon with the audience in a non-school environment, we aim to answer the central question: from the motivational aspects found in the participants of the activity in question, can we consider that they present evidences of intrinsic motivation and that astronomy was a motivating factor for their participation in the activity? For the study of motivation, we used as a theoretical framework the Self-Determination Theory, which studies the personality and human motivation as intrinsic and extrinsic motivations. To guide the analysis, we used the qualitative methodological framework of Textual Analysis Discourse that seeks to understand the new interpretations from the survey data. The research points out that Astronomy can be motivating in similar scenarios like the one presented in this work, because the data indicate evidences of intrinsic motivation of the participants. The results showed that non-school spaces of education can help the school work in literacy and scientific literacy of the community, thus showing the importance of developing such activities to aid learning.
\end{abstract}

Keywords: Astronomy Education; Non-school Environments; Theory of Self-determination; Motivation.

\title{
I. Introdução
}

Apesar de a Astronomia ser considerada por muitos autores como uma ciência atraente para o público geral, encontra-se hoje uma grande quantidade de concepções alternativas acerca do tema, indicando que um conteúdo pode não ser necessariamente compreendido, mesmo que seja atraente ou motivador. Pesquisas como a de Langhi e Nardi (2007) apontam 
que um dos fatores que contribuem para essas concepções é a falta de divulgação e de atividades relacionadas à Astronomia em escolas e em ambientes não escolares.

Reforçando a evidência da falta de atividades relacionadas com a Astronomia nas escolas ou em outros ambientes não escolares, o trabalho de Alves e Jafelice (2005) apresenta um levantamento identificando quantos estudantes da rede pública estadual de ensino da cidade de Natal (RN) já haviam realizado algum tipo de observação astronômica. Esses autores chegaram à conclusão de que 79\% dos estudantes da rede pública do RN nunca observaram o céu noturno utilizando algum instrumento óptico como um telescópio, um binóculo ou uma luneta, evidenciando a carência de atividades de divulgação em Astronomia realizadas na região.

As pesquisas sobre Educação em Astronomia mostram que existe um desconhecimento da população em geral sobre este tema, principalmente sobre a Astronomia Observacional, a qual é apresentada como um dos sete principais temas em Astronomia explorados por diversos autores, segundo um levantamento realizado por Langhi e Nardi (2010). Alves e Zanetic (2008) apontam que alguns espaços ditos como espaços de educação não formal (neste texto, trataremos como ambiente não escolar - ver Fig. 1) como, por exemplo, planetários, clubes de Astronomia amadora e observação realizada em praças, apresentam atividades que nos permitem trabalhar essas problemáticas, principalmente por meio das práticas com o telescópio e observações astronômicas.

A divulgação científica tem sido um caminho para a comunidade compreender a ciência sob outros aspectos fora do ambiente formal de ensino, pois "além de tornar o assunto compreensível para o grande público, ela estimula especialmente os estudantes a participar da grande aventura da busca do conhecimento" (ZIMMERMANN; MAMEDE, 2005). Um levantamento bibliográfico realizado por Martins (2014) apresenta uma síntese em forma de esquema com sugestões de definições para os espaços de ensino, conforme indicada pela Fig. 1.

Embora o discurso comum da literatura acadêmica das pesquisas sobre Educação em Astronomia seja o de que a Astronomia é motivadora, não encontramos em nosso levantamento bibliográfico quaisquer fundamentações teóricas e nem estudos específicos sobre motivação no estudo da Astronomia (MARTINS, 2014). Diversos trabalhos afirmam que a Astronomia é de fato motivadora (LANGHI, 2004), mas estes não se baseiam em nenhum referencial teórico sobre motivação como apoio. Assim, levantamos o seguinte questionamento inicial: a Astronomia pode ser realmente considerada motivadora?

Por isso, propomos a verificação da existência de aspectos motivacionais da Astronomia em uma atividade de ensino não escolar a fim de verificar se nesta atividade a Astronomia foi de fato motivadora sob a luz de um referencial teórico da área. Portanto, a questão central desta pesquisa é: a partir dos aspectos motivacionais encontrados nos participantes da atividade em questão, podemos considerar que estes apresentaram indícios de motivação 
intrínseca e que a Astronomia foi realmente um fator motivacional para a participação na atividade?

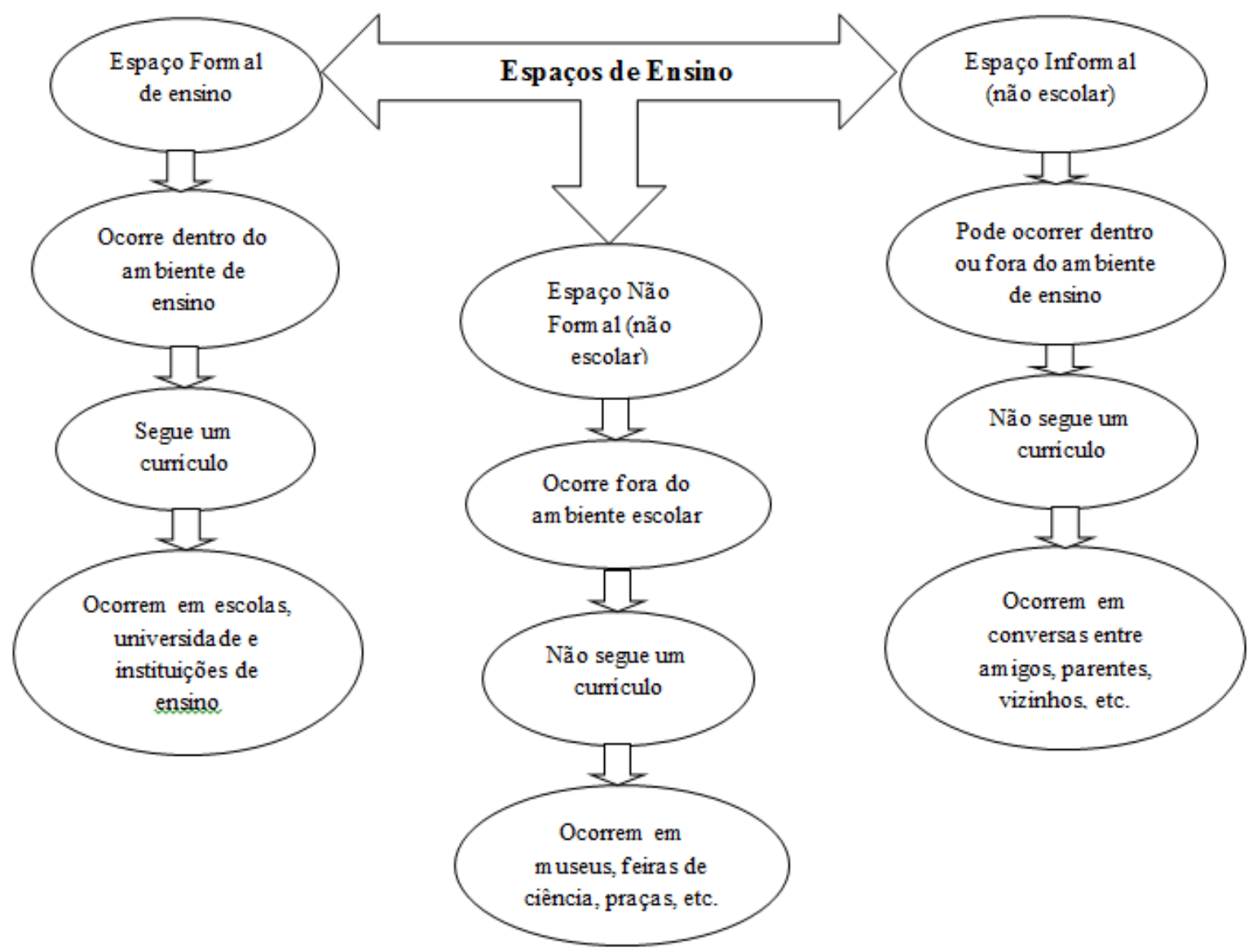

Fig. 1 -Definições sugeridas para os Espaços de Ensino. Fonte: Martins (2014).

Dentre inúmeras atividades a serem realizadas para verificar a motivação nos participantes, optamos pela Astronomia Observacional, devido à pouca divulgação e execução desse tipo de atividade no país e, principalmente, em Campo Grande (MS), pois na ocasião deste estudo não existia nenhum espaço específico de divulgação da Astronomia na cidade.

Refletindo sobre a natureza da Astronomia, essencialmente observacional, os PCN contemplam a importância das observações no ensino e divulgação das ciências, pois "observar não significa apenas ver, e sim buscar ver melhor, encontrar detalhes no objeto observado" (BRASIL, 1997). Denota-se, portanto, uma importância considerável em incluir observações do céu por meio de telescópios no ensino não formal e na divulgação de ciências, e não apenas a olho nu.

Em meio a tantos objetos astronômicos para observarmos no Universo por meio do telescópio, optamos pelo satélite natural da Terra, a Lua. Essa escolha justifica-se devido a este corpo celeste inserir-se dentre as sete principais concepções encontradas no público em geral, segundo a pesquisa de Langhi e Nardi (2010). 
A atividade observacional desta pesquisa foi executada em um ambiente não escolar e de contexto público e se prestou como fonte de dados para o objetivo central desta pesquisa, a saber, estudar quais aspectos motivacionais emergem a partir dos indivíduos transeuntes da Feira Central e Turística de Campo Grande (MS), quando participam da atividade observacional proposta nesta pesquisa.

\section{Referencial teórico}

A motivação é considerada um objeto de estudo da Psicologia. Pesquisas sobre o seu efeito na aprendizagem e desempenho têm representado um grande desafio à educação moderna, refletindo-se diretamente na eficácia do processo de ensino e aprendizagem.

Conforme Cavenaghi e Bzuneck (2009), "o termo motivação tem sua origem no verbo latino movere, cujo tempo supino motum e o substantivo motivum do latino tardio, deram origem ao termo aproximado motivo". O estudo da motivação consiste em analisar, estudar os fatores que levam os indivíduos a terem determinadas ações ou atitude dirigidas para que futuramente possam alcançar determinados objetivos, tarefas etc. A motivação possibilita a um indivíduo várias opções, oferecendo a ele recursos ideais, que tornarão possíveis suas escolhas autênticas, promovendo resultados satisfatórios, uma vez que ela aumenta o nível de interesse e compreensão, os quais geram aprendizagem.

Dentre as teorias da motivação, encontramos a proposta por Deci e Ryan (1985). Nesta, é apresentada uma macroteoria da motivação que os autores classificam como Teoria da Autodeterminação (TAD). Segundo eles, essa macroteoria possui a finalidade de compreender a personalidade da motivação humana, bem como a motivação intrínseca e extrínseca, analisando todos os aspectos favoráveis ou não para que a motivação possa ocorrer. Assim, essa teoria é a que mais se aproxima dos objetivos do trabalho em questão.

Segundo o estudo de Reeve, Deci e Ryan (2004), a autodeterminação é uma tendência humana inata e está relacionada à motivação intrínseca. Assim, os indivíduos realizam atividades de forma natural sem pressão externa sobre eles, estimulando as suas capacidades já existentes. Complementando esta ideia, Engelmann (2010) afirma que os contextos de convivência social podem fortalecer ou prejudicar o desenvolvimento das capacidades do indivíduo.

Por meio da perspectiva da TAD, foram elaboradas por Ryan e Deci (2002) quatro subteorias: Teoria das Necessidades Básicas, Teoria da Avaliação Cognitiva, Teoria da Orientação de Causalidade e Teoria da Integração Organísmica. Segundo estes autores, as três necessidades básicas psicológicas inatas, subjacentes à motivação intrínseca, e as formas mais autorreguladas de motivação extrínseca são propostas pela TAD: a necessidade de autonomia, a necessidade de competência e a necessidade de pertencer ou de estabelecer vínculos.

Segundo Guimarães e Boruchovitch (2004), a satisfação das três necessidades é considerada essencial para um desenvolvimento e saúde psicológica. Ainda segundo os mesmos autores, em um ambiente de ensino é preciso que a mesma seja fonte de satisfação dessas três 
necessidades psicológicas básicas para que a motivação intrínseca e as formas autodeterminadas de motivação extrínseca possam ocorrer.

Outro conceito introduzido por Guimarães e Boruchovitch (2004) está relacionado com a autonomia, que é a faculdade de se governar por si mesmo, o direito ou faculdade de se reger algo com leis próprias, liberdade ou independência moral ou intelectual. Para os mesmos autores, a necessidade de competência pode ser entendida como a capacidade do organismo de interagir satisfatoriamente com o meio onde se encontra, adquirindo assim maior segurança, confiança e eficiência para desenvolver determinadas atividades. Por outro lado, a necessidade de pertencimento está relacionada ao ato de estabelecer vínculo emocional, relações interpessoais, uma relação segura com os integrantes do meio.

Autonomia, para a TAD, não significa apresentar o desejo de aprender algo sozinho ou conseguir o conhecimento por conta própria, como um ato de individualismo ou desapego. Ao contrário, como apresentam Guimarães e Boruchovitch (2004), a autonomia pode ser entendida como buscar o conhecimento (ou algo) com ou sem ajuda, mas o que determina a autonomia, sob a visão desta fundamentação teórica, é que a vontade de aprender deve partir de si mesmo.

Reeve, Deci e Ryan (2004) consideram a necessidade de competência satisfeita quando o indivíduo busca e persiste em desafios adequados ao seu nível de desenvolvimento, mostra interesse em desenvolver atividades para seu crescimento psicológico e desenvolvimento das capacidades e habilidades próprias.

Somente a necessidade de competência não é suficiente para promover um aumento da motivação intrínseca. Segundo Guimarães e Boruchovitch (2004), torna-se necessário que a competência seja acompanhada por uma percepção de autonomia, ou seja, a situação não deve sufocar o senso de liberdade individual. Por outro lado, o indivíduo precisa se sentir responsável pelo desempenho competente.

Em relação à terceira necessidade, pertencer ou estabelecer vínculos, segundo Reeve, Deci e Ryan (2004), é considerada menos central quando comparada às demais, mas isso não significa que seja menos importante para a motivação intrínseca.

Sentir-se parte de um contexto, pertencer a este ambiente ou local, pode ser considerado como pano de fundo para a satisfação das outras necessidades: competência e autonomia (ENGELMANN, 2010). Quando essa necessidade é satisfeita, o indivíduo se sente motivado para o relacionamento autêntico com os indivíduos, aproximando-se daquelas que demonstram atenção e respeito em relação a eles (REEVE; DECI; RYAN, 2004).

De acordo com Ryan e Deci (2000), quando o ambiente possibilita suporte às necessidades de autonomia, competência e vínculo/pertencimento, os indivíduos sentem-se satisfeitos e envolvem-se ativamente nas atividades, possibilitando assim a manutenção ou o aumento da motivação intrínseca.

Os resultados de pesquisas como as apontadas no trabalho Reeve, Deci e Ryan (2004) sobre a teoria das necessidades básicas mostram que satisfazer as necessidades de $a u$ - 
tonomia, competência e vínculo permite encontrar satisfações favoráveis no indivíduo, promovendo um bem estar pessoal, enquanto a frustração dessas necessidades provoca mal estar e funcionamento precário do organismo.

Dentre as subteorias abordadas na TAD, o presente estudo focou estas três necessidades básicas, uma vez que apresentam termos considerados essenciais para o desenvolvimento psicológico e para a aprendizagem. Dentro da análise dos dados, também buscamos telementos que remetessem à motivação intrínseca e extrínseca descritos principalmente por Deci e Ryan (1985), emergentes dos participantes da atividade em questão.

\section{Metodologia}

Segundo os termos apresentados por Rosa (2011), essa pesquisa tem um delineamento de caráter empírico com intervenção, pois buscou na "realidade observável" os registros para obter seus dados e avaliar a extensão do efeito da intervenção feita pela pesquisa na população analisada. A pesquisa utilizou uma análise qualitativa dos dados obtidos, fundamentando-se na ATD, Análise Textual Discursiva (MORAES, 2003), privilegiando a interpretação escrita dos dados constituídos. Este estudo possui um delineamento não experimental, pois não queremos controlar variáveis, ou seja, não usamos grupos de controle. Portanto, há aqui um delineamento de caráter empírico não experimental qualitativo com intervenção.

A fase inicial desta pesquisa foi realizada uma vez por mês durante três meses consecutivos na semana da fase crescente da Lua, em um sábado, das 19h às 21h, na Associação da Feira Central e Turística de Campo Grande (MS). Uma equipe da UFMS (Universidade Federal de Mato Grosso do Sul) montou neste local um telescópio pertencente à Casa da Ciência (UFMS).

Qualquer indivíduo transeunte do local em questão (independentemente de idade, raça, escolaridade, classe social etc.) poderia realizar a observação da Lua por meio do telescópio. No local da atividade, os transeuntes interessados em participar da atividade foram conduzidos a uma fila única para que pudessem realizar a observação gratuitamente.

Em cada dia da atividade, após realizarem a observação, os participantes foram convidados a deixarem seus e-mails (para quem desejasse) digitando-os em um notebook disponível em uma mesa lateral. Os participantes que deixassem seus e-mails registrados eram informados que receberiam um questionário sobre a atividade realizada no dia e que, posteriormente, receberiam também um convite para retornarem em outras ocasiões.

Aos e-mails registrados em cada noite foi enviada uma mensagem na semana seguinte contendo um questionário, cujas respostas tornaram-se uma das fontes de dados para a presente pesquisa. Buscamos, por meio deste questionário, detectar indícios de motivação nos participantes ao observarem a Lua pelo telescópio.

Outra mensagem foi enviada posteriormente aos participantes dois dias antes da realização da atividade seguinte. Essa mensagem tinha o objetivo de relembrar os participantes 
da atividade anterior sobre outra oportunidade de observação da Lua no sábado seguinte. Deste modo, identificaríamos um possível interesse no retorno à atividade.

O questionário utilizado nesta pesquisa contém duas questões abertas e duas questões fechadas. Outra questão, classificada como "mista", é uma questão fechada em que o participante possui duas alternativas e, ao fazer sua escolha, deve justificá-la por escrito. Assim, o questionário desta pesquisa constituiu-se em cinco questões referentes à atividade de observação da Lua realizada.

As questões tinham como objetivo identificar indícios de motivação intrínseca ou extrínseca nas respostas dos participantes durante a atividade de observação. Somente os questionários respondidos e reenviados via e-mail foram considerados como fonte de dados para esta pesquisa, seguindo as orientações metodológicas e de técnicas de coleta de dados delineadas em Gil (2008).

O início do processo de validação do questionário desta pesquisa se deu com um esboço inicial do mesmo, o qual foi encaminhado para especialistas da área de Educação em Astronomia e da Teoria da Autodeterminação, a fim de exporem suas críticas e pareceres. Todas as observações enviadas pelos especialistas sobre o questionário foram analisadas cuidadosamente e aplicadas com vistas à sua adequação e validação. Após as mudanças efetuadas no questionário, o mesmo foi submetido a um teste piloto, ou seja, o questionário foi aplicado em um grupo de sujeitos que não integrou os resultados da pesquisa. Em seguida, realizaram-se as modificações necessárias no questionário e, consequentemente, chegou-se a uma versão final validada pelos especialistas e por um comitê de ética (esta pesquisa, incluindo o questionário, foi submetida ao comitê de ética da UFMS e aprovada junto à Plataforma Brasil, sob o registro $\mathrm{n}^{\circ}$ 08073712.0.0000.0021).

Além das respostas aos questionários, as anotações de campo efetuadas pelo pesquisador num "diário de bordo", conforme sugeridas por Flick (2009), constituíram o corpus de estudo. Por meio da Análise Textual Discursiva (ATD), proposta por Moraes (2003), seguimos três componentes: desconstrução dos textos do corpus (unitarização), estabelecimento de relações entre os elementos unitários ( a categorização) e o captar do novo emergente em que a nova compreensão é comunicada e validada.

\section{Análise de dados e resultados}

Além dos e-mails registrados em cada noite de atividade, foram recolhidas também informações sobre a faixa etária e o gênero de cada participante, a fim de caracterizarmos o grupo de análise. No quadro 1, são apresentadas as faixas etárias e os gêneros mais comuns encontrados nas observações. A faixa etária foi separada a cada dez anos para uma melhor organização.

O total de 482 participantes indicado no quadro foi o número considerado nesta pesquisa, mesmo que a quantidade de participantes na atividade tenha sido maior, pois muitos não forneceram seus dados e e-mails. Devido à grande procura pela atividade e a um número 
pequeno de monitores para atender as pessoas, não foi possível coletar os dados de todos os visitantes que realizaram a observação da Lua pelo telescópio.

Por meio dos dados coletados, constata-se um equilíbrio entre os gêneros masculino e feminino, o que indica neste caso a não preferência maior da parte de um gênero em relação a outro para a realização da atividade de observação da Lua.

Quadro 1 - Dados totais das observações (Fonte: autor).

\begin{tabular}{|c|c|c|}
\hline Sexo & Idade & Quantidade \\
\hline $33 \mathrm{M} \mathrm{e} 31 \mathrm{~F}$ & 0 até 10 anos & 64 pessoas \\
\hline $61 \mathrm{Me} 58 \mathrm{~F}$ & 11 até 20 anos & 119 pessoas \\
\hline $44 \mathrm{M} \mathrm{e} 40 \mathrm{~F}$ & 21 até 30 anos & 84 pessoas \\
\hline $43 \mathrm{M} \mathrm{e} 49 \mathrm{~F}$ & 31 até 40 anos & 92 pessoas \\
\hline $35 \mathrm{M}$ e $33 \mathrm{~F}$ & 41 até 50 anos & 68 pessoas \\
\hline $10 \mathrm{M} \mathrm{e} 13 \mathrm{~F}$ & 51 até 60 anos & 23 pessoas \\
\hline $10 \mathrm{M} \mathrm{e} 7 \mathrm{~F}$ & 61 até 70 anos & 17 pessoas \\
\hline $7 \mathrm{M} 2 \mathrm{~F}$ & 71 até 80 anos & 9 pessoas \\
\hline $3 \mathrm{M}$ e $3 \mathrm{~F}$ & 81 até 90 anos & 6 pessoas \\
\hline $\begin{array}{l}246 \text { Homens e } \\
236 \text { Mulheres }\end{array}$ & $\begin{aligned} \mathrm{M} & =\text { Masculino } \\
\mathrm{F} & =\text { Feminino }\end{aligned}$ & $\begin{array}{c}482 \text { pessoas e } \\
287 \text { e-mails reco- } \\
\text { lhidos }\end{array}$ \\
\hline
\end{tabular}

A grande participação das crianças e adolescentes detectada nesta pesquisa vai ao encontro do que comentam Kantor (2001), Langhi (2009 e 2004), dentre outros, de que a Astronomia chama a atenção principalmente desta faixa etária, uma vez que essa ciência possui atividades lúdicas, as quais, de alguma forma, os maravilham, pois confrontam as concepções e mitos que possuem sobre a Astronomia, despertando assim a sua imaginação.

O maior número de participantes esteve entre 11 e 20 anos de idade, abrangendo tanto a infância como a adolescência. Mas, um fato a ser destacado foi a grande participação de indivíduos com idade considerada adulta, que variou entre 21 a 50 anos, mostrando que a atividade despertou a curiosidade de todas as faixas etárias.

Seguindo o referencial metodológico adotado, nossa análise baseia-se em uma desconstrução, unitarização e categorização do corpus do conjunto de dados constituídos a partir das respostas dos questionários e dos registros do diário de campo do pesquisador. Procuramos, durante esta etapa da ATD, fragmentar cada aspecto que possa indicar indícios de motivação intrínseca ou extrínseca nos participantes da atividade. O primeiro passo para a análise do corpus é adotar um referencial teórico, pois segundo Moraes (2003), o estudo deste se torna inviável sem um referencial teórico para se concretizar. Portanto, como já apresentado, o referencial teórico adotado nesta análise é a Teoria da Autodeterminação (TAD).

Sob a luz da ATD (MORAES, 2003) e considerando que antes da análise já possuíamos um objetivo central nesta pesquisa, adotamos o método dedutivo, ou seja, as categorias 
foram definidas a priori antes da leitura do corpus de análise, seguindo os objetivos da pesquisa por meio do referencial teórico, uma vez que nosso referencial metodológico dá margem para tal procedimento (MORAES, 2003). Apesar de existirem categorias definidas a priori, não descartamos o surgimento de novas categorias após a análise do corpus, ou seja, há possibilidades de categorias emergentes, sendo obtidas por meio do método indutivo, segundo Moraes (2003).

No presente estudo, as análises evoluíram conforme as seguintes categorias a priori:

1) Autonomia;

2) Competência;

3) Pertencimento.

Devido ao espaço reduzido deste artigo, não será possível compartilhar integralmente as respostas obtidas nos questionários, mas apresentaremos o objetivo de cada pergunta, o que pretendíamos identificar nas respostas dos participantes e o que elas representam para a pesquisa.

\section{- Questionário e análise das respostas}

1. Você já realizou esse tipo de observação conosco?

( ) Sim.

( ) Não, foi a minha primeira observação aqui.

Nesta questão, buscamos identificar quais indivíduos participaram pela primeira vez e quais estavam participando pela segunda ou terceira vez da atividade. Caso um indivíduo já tivesse participado anteriormente da atividade, concluímos que este apresentou indícios de motivação perante ela, uma vez que por ter participado da atividade novamente, essa lhe proporcionou elementos que o motivaram internamente ao observar a Lua pelo telescópio. Assim, identificamos segundo o referencial teórico da TAD aspectos de autonomia, competência e pertencimento o que indica indícios de motivação intrínseca no participante ao realizar a atividade.

2. Você pretende voltar se puder outras vezes para observar a Lua pelo telescópio? Marque uma alternativa em que você se identifica para cada item.

\section{Item 1:}

( ) Sim, pois durante a observação eu me senti gratificado com a atividade;

( ) Não, pois durante a observação eu não me senti gratificado com a atividade.

Neste item, buscamos identificar indícios de competência nos participantes, uma vez que a capacidade destes de interagir satisfatoriamente com a atividade pode proporcionar uma maior segurança e confiança para realizá-la, assim como aponta Guimarães e Boruchovitch (2004). Essa gratificação seria um indício de motivação para o próprio participante. 


\section{Item 2:}

( ) Sim, pois não senti dificuldades em entender o que foi observado e explicado;

( ) Não, pois senti dificuldades em entender o que foi observado e explicado.

Neste item, buscamos identificar indícios de competência nos participantes, pois ao dominar uma atividade, o aumento da competência pode acontecer de maneira instantânea, podendo trazer emoções positivas e benefícios psicológicos que favorecem a motivação e também o aprendizado, como aponta Guimarães e Boruchovitch (2004).

\section{Item 3:}

( ) Sim, pois eu me senti capaz de aprender mais sobre o assunto;

( ) Não, pois eu não me senti capaz de aprender mais sobre o assunto.

Como apontam Reeve, Deci e Ryan (2004), quando o indivíduo busca algo além da atividade, ou seja, desafios adequados ao seu nível cognitivo, mostra o interesse de desenvolver suas habilidades sobre o tema. Assim, a atividade realizada pode ter proporcionado um desenvolvimento psicológico, mostrando indícios de motivação neste participante no domínio da competência.

\section{Item 4:}

( ) Sim, pois eu achei o local apropriado para a atividade;

( ) Não, pois eu não achei o local apropriado para a atividades.

Aqui, temos o elemento pertencimento, pois conforme demonstrado por Engelmann (2010), para ocorrer a motivação o indivíduo deve-se sentir de alguma forma parte do ambiente em que se encontra, ou seja, deve-se pertencer ao local. Esse item do questionário permitiu identificar se os participantes sentiram-se pertencentes ao local da atividade.

\section{Item 5:}

( ) Sim, pois me senti interessando em participar desta e de outras atividades envolvendo a Astronomia;

( ) Não, pois não me senti interessado em participar desta e de outras atividades envolvendo a Astronomia.

Neste item, os indícios de autonomia, competência e pertencimento puderam ser estudados, pois se o participante da atividade se sentir interessado em participar novamente desta atividade, ou de outras relacionadas à Astronomia, revelam-se indícios de motivação intrínseca, uma vez que segundo Ryan e Deci (2000), quando um indivíduo mostra o interesse de estar em um ambiente, de participar da atividade e buscar mais informações sobre esta, deixa evidente as três necessidades básicas essenciais para a motivação interna de um indivíduo.

3. Você realizou a observação por vontade própria ou alguém externo (familiares, amigos etc.) pediu a você para vir realizar a observação? 
Nesta questão a autonomia foi investigada, pois aqui identificamos quem possuiu vontade própria para entrar na fila e observar a Lua pelo telescópio e quem foi influenciado por alguém externo a participar. Se o indivíduo participou da atividade por vontade própria, isso mostra, segundo Guimarães e Boruchovitch (2004), o seu ato de governar por si próprio, ou seja, mostra a sua liberdade de escolha e expressão, contribuindo para a sua autonomia e consequentemente para a motivação intrínseca (interna). Caso este tenha participado da atividade devido a alguém externo, a motivação interna pode não ocorrer, uma vez que este não teve liberdade de escolha, participando da atividade somente para satisfazer algo externo a ele, não apresentando a sua autonomia (motivação extrínseca ou externa).

Aqui, buscamos identificar também o locus de causalidade, ou seja, queremos identificar o local de origem da ação que motivou a participação da atividade, seja ela interna ou externa ao indivíduo. Segundo Guimarães e Boruchovitch (2004), os indivíduos que realizam uma atividade por vontade própria, ou seja, autônomos, possuem um locus de causalidade interna, já os que não são autônomos possuem um locus de causalidade externa.

Alguns exemplos das respostas dadas pelos participantes, tomadas como unidades de registro, ilustram o processo de análise acima descrito: "vontade própria"; "fui por causa do meu irmão porque eu não tinha visto antes mas se eu tivesse visto primeiro iria ver na hora também".

4. O que o motivou a realizar a observação da Lua pelo telescópio?

Esta questão visou complementar a anterior, pois identificamos aqui, por meio da origem do locus de causalidade, o que provocou a ação, ou seja, o que fez com que o indivíduo se sentisse autônomo ou não, frente à atividade.

Neste mesmo item, podemos encontrar as três características da motivação intrínseca, as quais, segundo Vallerand et al. (1992), são: motivação intrínseca para saber, motivação intrínseca para realizações e a motivação intrínseca para vivenciar estímulos. Além da motivação intrínseca, as repostas a esta questão forneceram as características da motivação extrínseca, as quais, segundo Ryan e Deci (2000), são: regulação externa, regulação introjetada, regulação identificada e regulação integrada.

Essas características das motivações intrínseca e extrínseca constituem-se em subcategorias de análise adotadas em nossa pesquisa com a finalidade de melhor compreender os aspectos motivacionais, encontrados nos participantes da atividade. A Análise Textual Discursiva (ATD) das respostas dos participantes apontou o que os motivaram a participar da atividade, sejam elementos internos ou externos a eles, permitindo-nos assim a classificar as características da sua motivação.

As seguintes unidades extraídas das suas respostas exemplificam a análise acima descrita: "curiosidade em fazer essa observação da lua, sempre achei a astronomia interessante"; "aprender um pouco mais sobre a lua e observar pelo telescópio algo que eu nunca tinha feito"; "interesse em estudar astronomia"; "curiosidade sobre a lua e a beleza dela"; "Eu sempre achei a lua muito interessante, quando vi o telescópio na feira não perdi tempo e 
entrei na fila"; "gosto de astronomia e sempre quis fazer alguma coisa envolvendo a astronomia”; "a própria lua já é uma motivação e ainda vista pelo telescópio muito legal”.

5. A interação dos monitores com você lhe agradou?

( ) Sim. Explique por que essa interação agradou você.

( ) Não. Explique por que essa interação não agradou você.

Esta questão possibilitou-nos identificar o pertencimento, pois compreendemos como ocorreu a interação dos participantes com os monitores da atividade. É importante que tal interação seja positiva, pois segundo Engelmann (2010) o indivíduo deve-se sentir aceito por todos à sua volta e ter uma relação segura com estes para que possa ocorrer a motivação. Ao identificar se essa relação com os monitores foi positiva ou não e tendo a sua justificativa, foi possível entender se houve o pertencimento no sentido da interação com os monitores, além do pertencimento sobre o local da atividade, que é apresentado no item 4 da questão 2.

Seguem alguns exemplos das repostas dos participantes que ilustram a dimensão motivacional do pertencimento: "porque todos os monitores foram muito atenciosos e não esperava encontrar isso na feira"; "porque deram atenção e explicaram tudo o que eu gostaria de saber"; "porque vi os esforços deles em ajudar-nos a observar"; "porque foram legais, simpáticos e atenciosos"; "São muito educados e atenciosos"; "fui bem acolhido por eles".

Após a análise de todos os questionários respondidos, e completadas as etapas de desconstrução, unitarização e categorização, segundo a ATD, apresentamos, no quadro 2, uma síntese dos principais aspectos e características motivacionais resultantes desta pesquisa.

Quadro 1 - Síntese dos principais aspectos motivacionais encontrados (fonte: o autor).

\begin{tabular}{|c|c|}
\hline CATEGORIAS/ SUBCATEGORIAS & UNIDADES (PALAVRAS-CHAVE) \\
\hline Autonomia & Vontade própria. \\
\hline Competência & $\begin{array}{c}\text { Gratificação; Competente; Capaz; Dificulda- } \\
\text { des; Buscar conhecimento. }\end{array}$ \\
\hline Pertencimento & $\begin{array}{c}\text { Interação; Local; Bem estar; Conduta; Dedica- } \\
\text { ção dos monitores; Bom atendimento dos mo- } \\
\text { nitores; Empenho dos monitores; Atenciosos; } \\
\text { Boa relação. }\end{array}$ \\
\hline Motivação intrínseca para saber & $\begin{array}{c}\text { Aprender; Compreender; Estudar; Entender; } \\
\text { Ler; Explorar. }\end{array}$ \\
\hline Motivação intrínseca para realizações & Realização; Oportunidade; Fazer algo novo. \\
\hline Motivação intrínseca para vivenciar & Curiosidade; Vontade; Interesse; Admiração; \\
estimulos & Novas sensações; Prazer. \\
\hline Regulação externa & Vontade externa; Satisfazer algo externo. \\
\hline Regulação integrada & Vontade própria; Incentivo externo. \\
\hline
\end{tabular}


Constatamos no trabalho de Engelmann (2010) que a técnica mais apropriada de detectar indícios de motivação intrínseca em um indivíduo é o uso de questionário, pois, ao escrever, o participante pode melhor expressar suas sensações frente à atividade, uma vez que as questões devem buscar internamente no indivíduo suas respostas. Além destes fatores, não encontramos nenhum trabalho ou alguma referência no referencial teórico da TAD ou da motivação que trabalhasse ou sugerisse a utilização de um diário de bordo como forma de coleta de dados. Em todos os casos estudados por especialistas da área, encontramos somente o uso do questionário em seus relatos de pesquisas publicadas (MARTINS, 2014).

Registramos 482 endereços de e-mails recolhidos nas três noites de observações. Destes, 90 retornaram com respostas automáticas de erro, ou seja, por algum motivo o questionário enviado via e-mail não chegou até estes participantes, talvez pelo fato de ter ocorrido algum problema na identificação de seu endereço eletrônico. Dos 392 e-mails restantes, recebemos um retorno de $53(13,5 \%)$ questionários respondidos.

Com a atividade concluída, chegamos a um total de 482 participantes registrados e 287 e-mails recolhidos. Com os dados registrados dos participantes, constatamos que obtivemos na atividade 58 profissões diferentes. Isso mostra que independentemente da profissão ou classe social destes, o interesse pela Astronomia estava presente em todos, mostrando que essa ciência pode vir a motivar indivíduos.

\section{Considerações}

Embora tenhamos registrado um baixo número de questionários respondidos e reenviados aos pesquisadores em comparação ao número de e-mails registrados em cada noite, isto não parece significar necessariamente que os não respondentes sentiram-se desmotivados de alguma forma frente a essa, uma vez que não sabíamos o contexto em que cada um se encontrava no momento a fim de não responderem os questionários. Por exemplo, desconhecemos se todos os participantes possuíam computadores ou acesso à internet em casa; se o $e$ mail enviado não foi para a caixa de spam; se o participante não possuiu um tempo necessário para responder ao questionário; se o e-mail respondido chegou de fato aos pesquisadores; ou se simplesmente não se interessaram em responder o questionário (por um motivo que não podemos constatar); entre outros fatores. Assim, podemos fazer afirmações sobre os resultados da pesquisa apenas a partir dos questionários respondidos e reenviados, tomando estes como base principal para a análise dos dados.

Por outro lado, podemos levantar alguns contrapontos e outros questionamentos que permanecem em aberto: por quais outros motivos reais os demais não retornaram o contato? Seria, de fato, evidência de desinteresse e desmotivação intrínseca e extrínseca sobre o assunto? Será que os participantes só decidiram observar a Lua devido ao fato de a atividade ter sido oferecida gratuitamente e apenas porque o telescópio estava ali à sua disposição justamente na ocasião em que estavam presentes na Feira com outros propósitos? 
Quanto à faixa etária, destacamos uma grande variação, mas de uma maneira proporcional em relação ao público que normalmente frequenta o local escolhido para a sua realização, que também costuma estar entre 0 a 90 anos, segundo informações da coordenação da Feira. Esta constatação revela que, seja qual for a faixa etária de um indivíduo, a curiosidade e a vontade de aprender um pouco sobre a Astronomia, ou alguma outra realização pessoal, o moveu a participar da atividade, concordando com as afirmações de Kantor (2001), Klein et al. (2010), Langhi (2004), dentre outros encontrados na literatura, de que independentemente da faixa etária, a Astronomia desperta de alguma forma a curiosidade de um indivíduo em ter um contato direto com essa ciência.

A partir dos aspectos motivacionais encontrados nos participantes da atividade, podemos concluir que $98,11 \%$ dos que responderam o questionário apresentaram indícios de motivação intrínseca ao participar da atividade em questão, ou seja, a partir dos questionários respondidos e analisados por meio do referencial teórico da TAD, verificou-se a sua motivação intrínseca. Apenas 1,9\% representa uma motivação extrínseca ao participar da atividade, sem apresentar aspectos da motivação intrínseca.

Portanto, finalmente podemos apresentar a última etapa da ATD do nosso estudo, a saber, a construção do "novo emergente", o qual responde satisfatoriamente a nossa questão de pesquisa: a partir da Análise Textual Discursiva dos aspectos motivacionais (fundamentados na Teoria da Autodeterminação) encontrados nos participantes de uma atividade de observação telescópica da Lua em um espaço não escolar, consideramos que os indivíduos apresentaram indícios de motivação intrínseca e, por isso, a Astronomia constitui-se em um fator motivacional para o interesse e participação na atividade.

Sendo assim, demonstramos com mais segurança e aporte teórico a concepção comumente encontrada na literatura de que a Astronomia pode ser considerada uma ciência motivadora. Ressaltamos que este foi um estudo específico para esta situação-problema e para este grupo de análise, isto é, os transeuntes da Feira Central e Turística da cidade de Campo Grande (MS). Não podemos afirmar se outras atividades diferentes envolvendo o estudo da Astronomia e em outros grupos de análise poderiam emergir os mesmos aspectos motivacionais. É igualmente importante citar que os instrumentos utilizados na atividade, como os painéis, folders, binóculo, e outros materiais, podem ter exercido influência nos resultados quanto aos indícios de motivação intrínseca nos participantes.

No entanto, nossos resultados ajudam a constatar que a divulgação cientifica em espaços não escolares de ensino pode apresentar um grande potencial para a aprendizagem, pois neste ambiente é possível encontrar indivíduos totalmente motivados intrinsicamente, sendo este um grande passo para o letramento e alfabetização científica da comunidade.

As atividades desenvolvidas neste ambiente não escolar demonstraram a possibilidade de uma importante complementaridade no processo de ensino e aprendizagem, como apontam Alves e Zanetic (2008). Assim, a responsabilidade de alfabetizar a comunidade não fica somente restrita à escola, uma vez que espaços não escolares também possuem uma caracte- 
rística que pode contemplar a aprendizagem: a característica da motivação intrínseca. Desta forma, o potencial do papel da educação não escolar em contribuir para a aprendizagem precisa ser aproveitado, pois pode oferecer o que muitas escolas não apresentam.

\section{Referências}

ALVES, M.T.S.; JAFELICE, L.C. Tópicos Astronômicos no Ensino Médio em Natal (RN): Características e Discussões. In: REUNIÃO ANUAL DA SAB, 31, 2005, Águas de Lindóia. Boletim da Sociedade Astronômica Brasileira, São Paulo: SAB, v. 25. p. 79-79, 2005.

ALVES, M. T. S.; ZANETIC, J. O ensino não formal da astronomia: um estudo preliminar de suas ações e implicações. In: ENCONTRO DE PESQUISA EM ENSINO DE FÍSICA, 11, 2008, Curitiba. Atas... Paraná: SBF, v. 11, p. 12-18, 2008.

BRASIL Ministério da Educação e Cultura. Parâmetros Curriculares Nacionais: ciências naturais. Brasília: MEC/SEMTEC, 1997.

CAVENAGHI, A. R. A.; BZUNECK, J. A. A motivação de alunos adolescentes enquanto desafio na formação do professor. In: CONGRESSO NACIONAL DE EDUCAÇÃO, 9, 2009, Curitiba. Atas... Paraná: PUCPR, p. 1478-1489, 2009.

DECI, E. L.; RYAN, R. M. Intrinsic motivation and self-determination in human Behavior. EUA: Plenum Press, 1985.

ENGELMANN, E. A motivação de alunos dos cursos de artes de uma universidade pública do norte do Paraná. 2010. Dissertação (Mestrado em Educação) - Centro de Educação, Comunicação e Artes, Departamento de Educação, UEL, Londrina.

FLICK, U. Introdução à pesquisa qualitativa. Porto Alegre: Artmode, 2009.

GUIMARÃES, S. E.R.; BORUCHOVITCH, E. O estilo motivacional do professor e a motivação intrínseca dos estudantes: uma perspectiva da teoria da autodeterminação. Psicologia: reflexão e crítica, v. 17, n. 2, p. 143-150, 2004.

GIL, A. C. Métodos e técnicas de pesquisa social. 6. ed. São Paulo: Atlas, 2008.

KANTOR, C. A. A ciência do céu: uma proposta para o ensino médio. 2001. Dissertação (Mestrado em Educação) - Instituto de Física, Departamento de Física Experimental, USP, São Paulo.

KLEIN, A. E. et al. Os sentidos da observação astronômica: uma análise com base na relação com o saber. Revista Latino-Americana de Educação em Astronomia, n. 10, p. 37-54, 2010. 
LANGHI, R. Um estudo exploratório para a inserção da Astronomia na formação de professores dos anos iniciais do Ensino Fundamental. 2004. 240 f. Dissertação (Mestrado em Educação para a Ciência) - Faculdade de Ciências, UNESP, Bauru.

LANGHI, R. Astronomia nos anos iniciais do ensino fundamental: repensando a formação de professores. 2009. Tese (Doutorado em Educação para a Ciência) - Faculdade de Ciências, UNESP, São Paulo.

LANGHI, R.; NARDI, R. Ensino de Astronomia: erros conceituais mais comuns presente em livros didáticos de ciências. Caderno Brasileiro de Ensino de Física, Florianópolis, v. 24, n. 1, p. 87-111, abr. 2007.

LANGHI, R.; NARDI, R. Formação de professores e seus saberes disciplinares em astronomia essencial nos anos iniciais do ensino fundamental. Ensaio Pesquisa em Educação em Ciências, Belo Horizonte, v. 12, n. 2, p.205-224, mai-ago. 2010.

MARTINS, B. A. Um estudo exploratório sobre os aspectos motivacionais de uma atividade não escolar para o ensino da Astronomia. 2014. Dissertação (Mestrado Profissional em Ensino de Ciências) - Instituto de Física, UFMS, Campo Grande.

MORAES, R. Uma tempestade de luz: a compreensão possibilitada pela Análise Textual Discursiva. Ciência \& Educação, Bauru, v. 9, n. 2, p. 191-211, 2003.

REEVE, J.; DECI, E. L.; RYAN, R. M. Self-determination theory: a dialectical framework for understanding sociocultural influences on student motivation. In: McINERNEY, D. M.; VAN ETTEN, S. (Ed.) Big theories revisited. Greenwich: Information Age Publishing, 2004. cap. 3, p. 31-60.

ROSA, P. R. S. Instrumentação para o ensino de ciências. Campo Grande: EDUFMS, 2011.

RYAN, R. M.; DECI, E. L. Intrinsic and extrinsic motivations: classic definitions and new directions. Contemporary Educational Psychology, n. 25, p. 54-67, 2000.

RYAN, R. M.; DECI, E. L. Overview of self-determination theory: an organismic dialectical perspective. In: DECI, E. L.; RYAN, R. M. (Ed.). Handbook of self-determination research. Rochester: University of Rochester Press, 2002.

VALLERAND, R. J. et al. The academic motivation scale: a measure of intrinsic, extrinsic, and a motivation in education. Educational and Psychological Measurement, v. 5, p. 1003$1017,1992$.

ZIMMERMANN, E.; MAMEDE, M. A. Novas direções para o Letramento Científico: pensando o Museu de Ciência e Tecnologia da Universidade de Brasília. In: REUNIÓN DE LA RED - POP, 9, 2005, Rio de Janeiro, Anais... Rio de Janeiro: Rede-Pop, v. 1, p. 23-38, 2005. 